\title{
MEDIA SOSIAL SEBAGAI SARANA PROMOSI PERPUSTAKAAN (Studi Kasus di Perpustakaan Universitas Airlangga)
}

\author{
Hoeroestijati \\ Perpustakaan Universitas Airlangga \\ e-mail: hoeroestijati@staf.unair.ac.id
}

\begin{abstract}
ABSTRAK
Perangkat teknologi informasi memungkinkan pengguna dapat terkoneksi dan berinteraksi. Interaksi ini dilakukan melalui sosial media. Media sosial merupakan media yang memungkinkan setiap orang berinteraksi dan berkomunikasi tanpa terhalang ruang dan waktu. Media Sosial Sebagai Sarana Promosi Perpustakaan sebuah Studi Kasus Di Perpustakaan Universitas Airlangga. Mengapa penulis menjadikan Perpustakaan Universitas Airlangga sebagai objek penelitian karena Perpustakaan Universitas Airlangga telah lama memiliki media sosial sebagai sarana informasi dan komunikasi. Perpustakaan Universitas Airlangga memiliki beberapa media sosial yaitu WhatsApp (wa), Facebook, Twitter, Line, Instagram, dan Youtube. Media sosial Perpustakaan Universitas Airlangga bertujuan untuk berinteraksi secara masif dan terstruktur dengan pengguna perpustakaan. Media sosial Perpustakaan Universitas Airlangga dikelola oleh Humas Perpustakaan Universitas Airlangga. Humas Perpustakaan Universitas Airlangga ini yang mengisi konten media sosial dan merespon pengguna yang bertanya atau memberikan masukan, kritik dan saran.
\end{abstract}

Kata Kunci: media sosial, WhatsApp (wa), facebook, twitter, line, instagram, dan youtube, perpustakaan

\section{PENDAHULUAN}

Perkembangan peradaban kehidupan manusia telah mengantarkan kita ke dalam suatu era yang serba canggih. Perkembangan kecanggihan teknologi yang paling terlihat adalah perkembangan teknologi informasi dan komunikasi yang berjalan sangat cepat. Teknologi informasi menjadi bagian dari kehidupan keseharian masyarakat. Kehidupan manusia seolah-olah tidak bisa dilepaskan dengan teknologi informasi dan komunikasi. Saat ini, manusia tidak asing lagi dengan Perangkat teknologi seperti handphone, smartphone, laptop, dan jenis gadget yang lain. Setiap orang akan memilih lebih baik tidak membawa dompet dari pada tidak membawa handphone atau smartphone.

Sebagian besar masyarakat menggunakan perangkat teknologi hampir dua pertiga waktu yang dimilikinya. Perangkat teknologi tersebut dapat dipakai untuk berbagai macam keperluan, untuk membantu proses belajar mengajar bagi pelajar, mahasiswa, dosen dan juga guru. Perangkat teknologi juga dapat membantu bekerja, memasak, melakukan perjalanan bahkan sampai mempelajari keterampilan baru. Semua hal tersebut dilakukan dengan mengandalkan perangkat teknologi.
Masyarakat menggunakan perangkat teknologi untuk melakukan komunikasi atau pun untuk mengakses informasi. Oleh karena itu, semua aktivitas manusia saat ini sangat tergantung juga dengan perangkat teknologi.

Perangkat teknologi informasi memungkinkan pengguna dapat terkoneksi. Generasi muda khususnya ini ingin selalu terkoneksi dengan dunia luar. Hal ini mendorong mengapa warung-warung kopi dan cafe senantiasa rame pengunjung. Bukan karena memiliki cita rasa menu yang luar biasa, tetapi karena tempat-tempat tersebut memiliki wifi gratis bagi setiap pengunjung. Melihat kenyataan di atas, terlihat bahwa beberapa lokasi komersial seperti rumah makan dan cafe telah menyadari pentingnya akses internet bagi pengunjungnya. Mereka menyadari bahwa akses wifi merupakan salah satu daya tarik orang untuk datang berkunjung dan betah berada di sana. Itu artinya makanan yang mereka jual akan laku. Apabila pengunjung betah berada di sana, itu juga berarti bahwa makanan dan atau minuman yang mereka tawarkan semakin banyak yang terjual.

Mengapa generasi muda atau milenial sangat menggandrungi wifi. Jawabannya karena mereka ingin terkoneksi dengan dunia luar. Mereka ingin berinteraksi dengan pihak-pihak lain di luar lingkungan mereka sehari- 
hari. Milenial ingin mengikuti perkembangan terbaru dan mengikuti tren-tren yang terjadi di luar. Interaksi ini dilakukan melalui sosial media. Media sosial merupakan media yang memungkinkan setiap orang berinteraksi dan berkomunikasi tanpa terhalang ruang dan waktu. Hingga saat ini, media sosial sudah menjadi gaya hidup. Seorang milenial dikatakan tidak "gaul" jika tidak akrab dengan media sosial. Komunikasi antar milenial saat ini juga senantiasa memanfaatkan internet dan media sosial.

Besarnya minat masyarakat Indonesia terhadap media sosial dapat dilihat dari data tersebut. Pada akhirnya, media sosial mengalami perkembangan yang sangat menakjubkan. Media sosial diklaim memiliki banyak manfaat. Perpustakaan sebagai salah satu institusi yang dapat memanfaatkan media sosial sebagai media informasi dan komunikasi. Komunikasi melalui media sosial antara perpustakaan dan pengguna dipandang jauh lebih efektif dari pada jenis komunikasi konvensional yang lebih dahulu ada, seperti poster yang ditempel, undangan tercetak, selebaran-selebaran dan lain sebagainya.

Hal ini menjadikan penulis berkeinginan untuk menulis tentang Media Sosial Sebagai Sarana Promosi Perpustakaan sebuah Studi Kasus Di Perpustakaan Universitas Airlangga. Mengapa penulis menjadikan Perpustakaan Universitas Airlangga sebagai obyek penelitian karena Perpustakaan Universitas Airlangga telah lama memiliki media sosial sebagai sarana informasi dan komunikasi.

\section{Kajian Teori}

Selain pernyataan diatas, berikut ini adalah definisi dari media sosial yang berasal dari berbagai literatur penelitian (Fuchs, 2014 dalam Nasrullah, 2015:

a. Menurut Kaplan dan Haenlein (2010) media sosial merupakan sekelompok aplikasi yang berbasiskan pada internet dan dibangun berdasarkan kerangka pikiran ideologi dan teknologi dari platform Web 2.0, medium ini dapat menghubungkan individu dengan individu untuk saling berbagi dan berkumpul secara online.

b. Boyd (2009), menjelaskan media sosial sebagai kumpulan perangkat lunak yang memungkinkan individu maupun komunitas untuk berkumpul, berbagi, berkomunikasi dan dalam kasus tertentu saling berkolaborasi atau bermain. Media sosial memiliki kekuatan pada user generated content (UGC) dimana konten dihasilkan oleh pengguna, bukan oleh editor sebagaimana di institusi media massa. c. Carr dan Hayes (2015) mendefinisikan media sosial adalah media berbasis internet yang memungkinkan pengguna berkesempatan untuk berinteraksi dan mempresentasikan diri, baik secara seketika ataupun tertunda, dengan khalayak luas maupun tidak yang mendorong nilai dari user-generated content dan persepsi interaksi dengan orang lain

d. Sedangkan menurut Phillip Kotler dan Kevin Keller (2012) media sosial adalah sarana bagi konsumen untuk berbagi informasi teks, gambar, video dan audio dengan satu sama lain dan dengan perusahaan dan sebaliknya

Secara singkat dapat didefinisikan bahwa media sosial adalah segala bentuk media komunikasi interaktif yang memungkinkan terjadinya interaksi dua arah dan umpan balik. Media sosial adalah medium di internet yang memungkinkan pengguna merepresentasikan dirinya maupun berinteraksi, bekerja sama, berbagi, berkomunikasi dengan pengguna lain, dan membentuk ikatan sosial secara virtual. Media sosial merupakan sebuah media online dimana setiap penggunanya bisa bebas untuk saling berbagi atau berpartisipasi baik itu informasi maupun hiburan yang mampu mendukung adanya interaksi sosial.

Selain itu terdapat pendapat lain menurut Puntoadi (2011), yaitu pengguna media sosial berfungsi sebagai berikut:

1. Keunggulan membangun personal branding sosial media adalah tidak mengenal trik atau popularitas semu, karena audensilah yang menentukan. Berbagai media sosial menjadi media untuk orang berkomunikasi, berdiskusi dan bahkan memberikan sebuah popularitas di media sosial.

2. Media sosial memberikan sebuah kesempatan yang berfungsi untuk berinteraksi lebih dekat dengan konsumen. Media sosial menawarkan sebuah konten komunikasi yang lebih individual. Melalui media sosial pula berbagai para pemasar dapat mengetahui kebiasaan dari konsumen mereka dan melakukan suatu interaksi secara personal, serta dapat membangun sebuah ketertarikan yang mendalam.

Media sosial memiliki beberapa karakter yang tidak dimiliki oleh beberapa jenis media lainnya. Ada batasan maupun ciri khusus yang hanya dimiliki oleh media sosial. Berikut beberapa karakteristik media sosial yaitu (Nasrullah, 2015):

1. Jaringan

Media sosial terbangun dari struktur sosial yang terbentuk dalam jaringan atau internet. Karakter 
media sosial adalah membentuk jaringan diantara penggunanya sehingga kehadiran media sosial memberikan media bagi pengguna untuk terhubung secara mekanisme teknologi.

2. Informasi

Informasi menjadi hal yang penting dari media sosial karena dalam media sosial terdapat aktifitas memproduksi konten hingga interaksi yang berdasarkan informasi.

3. Arsip

Bagi pengguna media sosial arsip merupakan sebuah karakter yang menjelaskan bahwa informasi telah tersimpan dan bisa diakses kapanpun dan melalui perangkat apapun.

4. Interaksi

Karakter dasar dari media sosial adalah terbentuknya jaringan antar pengguna. Fungsinya tidak sekedar memperluas hubungan pertemanan maupun memperbanyak pengikut di internet. Bentuk sederhana yang terjadi di media sosial dapat berupa memberi komentar dan lain sebagaiannya.

5. Simulasi Sosial

Media sosial memiliki karakter sebagai media berlangsungnya masyarakat di dunia virtual (maya). Ibarat sebuah Negara, media sosial juga memiliki aturan dan etika bagi para penggunanya. Interaksi yang terjadi di media sosial mampu menggambarkan realitas yang terjadi akan tetapi interaksi yang terjadi adalah simulasi yang terkadang berbeda sama sekali.

6. Konten oleh Pengguna

Karakteristik ini menunjukkan bahwa konten dalam media sosial sepenuhnya milik dan juga berdasarkan pengguna maupun pemilik akun. Konten oleh pengguna ini menandakan bahwa di media sosial khalayak tidak hanya memproduksi konten mereka sendiri melainkan juga mengkonsumsi konten yang diproduksi oleh pengguna lain.

7. Penyebaran

Penyebaran adalah karakter lain dari media sosial, tidak hanya menghasilkan dan mengkonsumsi konten tetapi juga aktif menyebarkan sekaligus mengembangkan konten oleh penggunanya.

Media sosial dirasakan memiliki banyak fungsi bagi penggunanya. Menurut Puntoadi (2011), yaitu pengguna media sosial berfungsi sebagai berikut:

a) Keunggulan membangun personal branding melalui sosial media adalah tidak mengenal trik atau popularitas semu, karena audensilah yang menentukan. Berbagai media sosial menjadi media untuk orang berkomunikasi, berdiskusi dan bahkan memberikan sebuah popularitas di media sosial.

b) Media sosial memberikan sebuah kesempatan yang berfungsi untuk berinteraksi lebih dekat dengan konsumen. Media sosial menawarkan sebuah konten komunikasi yang lebih individual. Melalui media sosial pula berbagai para pemasar dapat mengetahui kebiasaan dari konsumen mereka dan melakukan suatu interaksi secara personal, serta dapat membangun sebuah ketertarikan yang mendalam.

Menurut Kaplan dan Haenlein (2010), media sosial dikelompokkan dalam enam jenis, yaitu:

1. Proyek kolaborasi website, di mana user-nya diizinkan untuk dapat mengubah, menambah, atau pun membuang konten-konten yang termuat di website tersebut, seperti Wikipedia.

2. Blog dan microblog, di mana user mendapat kebebasan dalam mengungkapkan suatu hal di blog itu, seperti perasaan, pengalaman, pernyataan, sampai kritikan terhadap suatu hal, seperti Twitter.

3. Konten atau isi, di mana para user di website ini saling membagikan konten-konten multimedia, seperti e-book, video, foto, gambar, dan lain-lain seperti Instagram dan Youtube.

4. Situs jejaring sosial, di mana user memperoleh izin untuk terkoneksi dengan cara membuat informasi yang bersifat pribadi, kelompok atau sosial sehingga dapat terhubung atau diakses oleh orang lain, seperti misalnya Facebook.

5. Virtual game world, di mana pengguna melalui aplikasi 3D dapat muncul dalam wujud avataravatar sesuai keinginan dan kemudian berinteraksi dengan orang lain yang mengambil wujud avatar juga layaknya di dunia nyata, seperti online game.

6. Virtual social world, merupakan aplikasi berwujud dunia virtual yang memberi kesempatan pada penggunanya berada dan hidup di dunia virtual untuk berinteraksi dengan yang lain. Virtual social world ini tidak jauh berbeda dengan virtual game world, namun lebih bebas terkait dengan berbagai aspek kehidupan, seperti Second Life.

\section{Metode Penelitian}

Menurut Nawawi (1993), penelitian kualitatif adalah proses menjaring informasi dan kondisi yang sebenarnya dalam kehidupan suatu objek yang dihubungkan dengan pemecahan suatu masalah baik dari sudut pandang teoritis 
maupun praktis. Penelitian ini menggunakan pendekatan kualitatif dengan jenis deskriptif dan metode studi kasus agar penelitian dapat dilakukan secara mendalam dan menyeluruh. Peneliti mengamati fenomena media sosial khususnya yang telah dilaksanakan oleh Perpustakaan Universitas Airlangga.

\section{PEMBAHASAN}

\section{Media Sosial Perpustakaan Universitas Airlangga}

Perpustakaan Universitas Airlangga memiliki beberapa media sosial. Media sosial Perpustakaan Universitas Airlangga bertujuan untuk berinteraksi secara masif dan terstruktur dengan pengguna perpustakaan. Media sosial Perpustakaan Universitas Airlangga dikelola oleh Humas Perpustakaan Universitas Airlangga. Humas Perpustakaan Universitas Airlangga ini yang mengisi konten media sosial dan merespon pengguna yang bertanya atau memberikan masukan, kritik dan saran.

Media Sosial Perpustakaan Universitas Airlangga antara lain:

\section{WhatsApp (wa)}

WhatsApp adalah aplikasi chatting yang memungkinkan penggunanya untuk berbagi file dan gambar, serta melakukan panggilan suara dan video call secara gratis. WhatsApp juga dapat dimanfaatkan sebagai alat promosi yang efektif namun sifatnya personal.

WhatsApp (wa) Perpustakaan Universitas Airlangga merupakan salah satu media sosial yang dimiliki oleh Perpustakaan Universitas Airlangga. Melalui WhatsApp (wa), Perpustakaan Universitas Airlangga menyampaikan informasi terkini tentang perpustakaan. Berita terbaru dan kondisi perpustakaan terkini masuk dalam WhatsApp (wa) Perpustakaan Universitas Airlangga. Pemustaka dapat mengetahui perkembangan terbaru perpustakaan melalui WhatsApp (wa).

Pemustaka dapat bertanya secara langsung kepada humas seputar masalah perpustakaan. Pihak humas akan segera menjawab setiap pertanyaan yang masuk dalam

WhatsApp (wa) UNAIR LIB. WhatsApp (wa) Perpustakaan Universitas Airlangga juga menginformasikan mengenai info-info kegiatan di perpustakaan, misal seperti seminar, talkshow, musik akustik, bazar, call for paper dan lain-lain. Pemustaka dapat menghubungi admin Perpustakaan

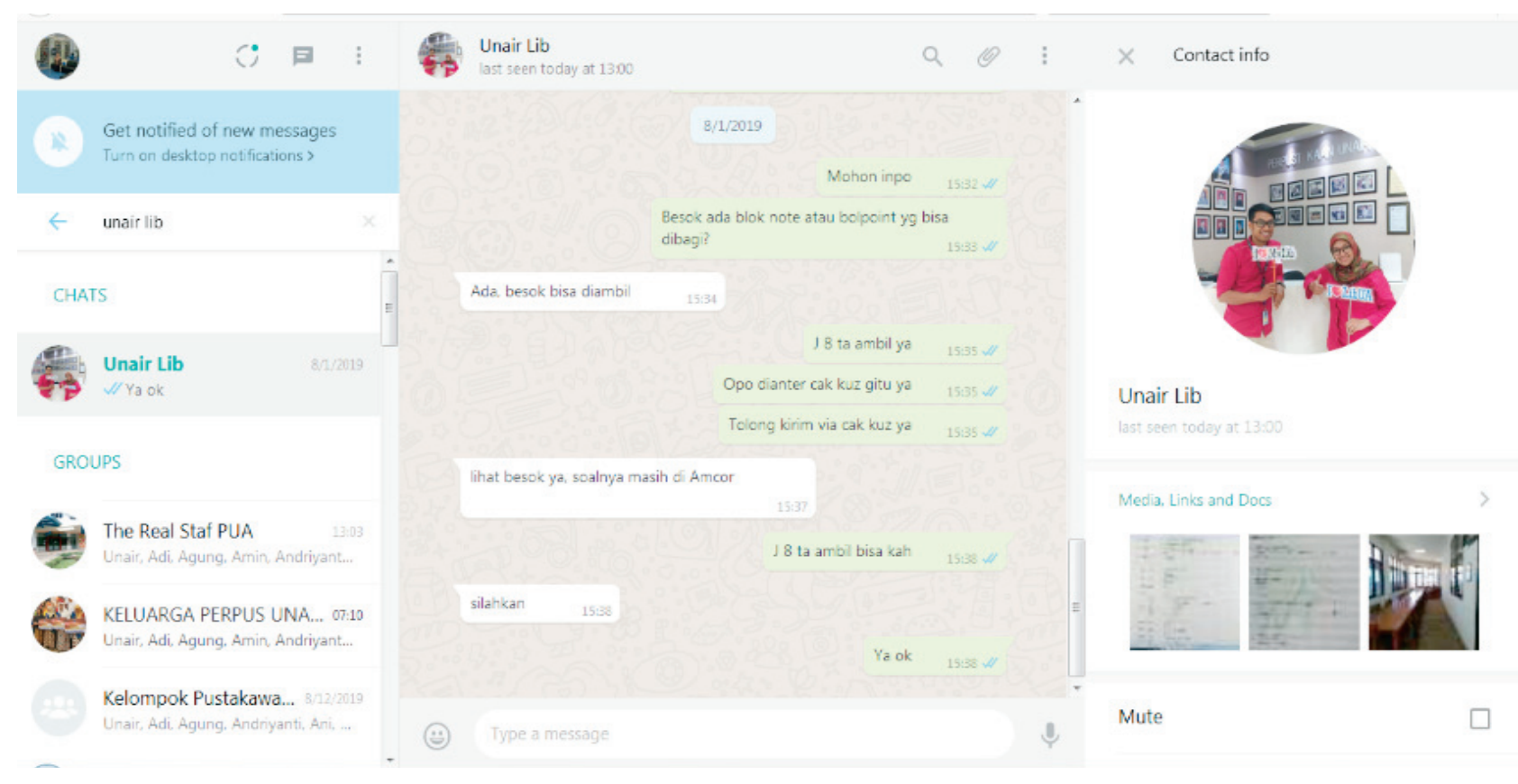

Gambar 1. WhatsApp (wa) Perpustakaan Universitas Airlangga 


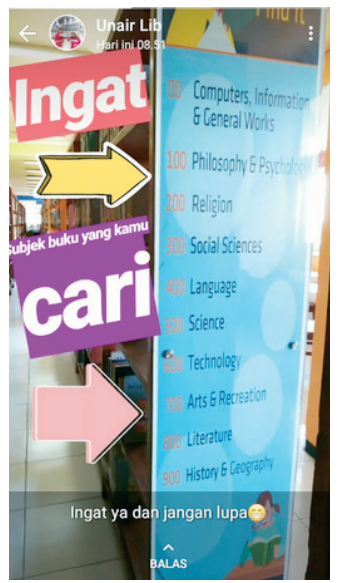

Gambar 2. Stories WhatsApp (wa) Perpustakaan Universitas Airlangga

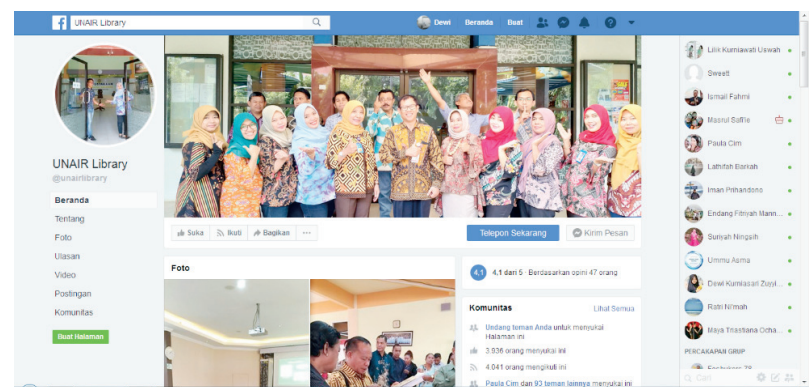

Gambar 3. Facebook Perpustakaan Universitas Airlangga

Universitas Airlangga dengan nomor WhatsApp +62 82231517409 .

2. Facebook

Facebook memang sudah lewat masa kejayaannya. Namun masih digemari oleh beberapa kalangan. Facebook masih dianggap efektif dan efisien dalam menyampaikan informasi, merepresentasikan suatu lembaga dan berjejaring. Facebook mampu memberikan feedback secara langsung sehingga tercipta komunikasi antar pribadi. Untuk itu, Perpustakaan Universitas Airlangga memiliki facebook untuk menampilkan produk dan layanan serta dapat menjalin komunikasi dengan para pemustaka. Facebook Perpustakaan Universitas Airlangga memiliki alamat facebook.com/ unairlibrary.

3. Twitter

Twitter adalah salah satu media sosial terpopuler abad ini. Selain penggunaannya yang mudah, twitter mempunyai pengguna yang sangat banyak. Banyaknya

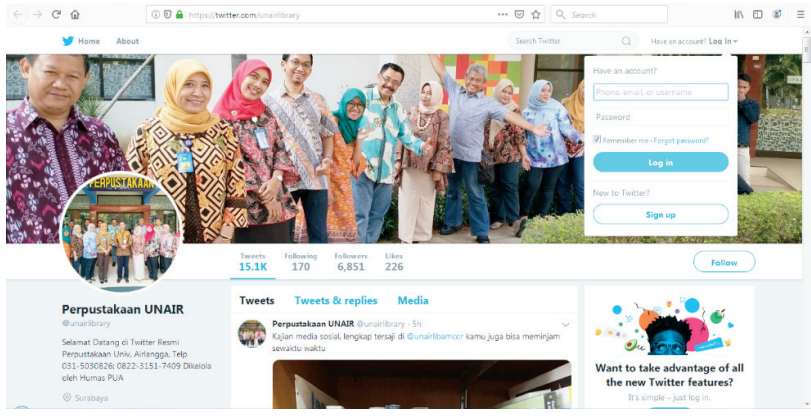

Gambar 4. Twitter Perpustakaan Universitas Airlangga

pengguna Twitter ini merupakan pangsa pasar potensial. Perpustakaan Universitas Airlangga juga memanfaatkan twitter untuk memberikan informasi dan berkomunikasi dengan pemustaka. Dengan kicauan dari @unairlibrary menginformasikan tentang layanan terbaru perpustakaan, barang pemustaka yang ketinggalan. Bahkan juga dapat digelar voting terhadap suatu hal misal tentang ruang mana yang paling diminati oleh pemustaka, buku apa yang paling menarik dan lain sebagainya. Twitter Perpustakaan Universitas Airlangga dengan alamat https:/twitter.com/unairlibrary, memiliki follower 6.908, likes 248 , telah melakukan tweets sebanyak $15.6 \mathrm{~K}$, following 172.

4. Line

Line merupakan media sosial untuk mengirim pesan secara gratis yang dapat digunakan dalam berbagai platform, misal smartphone, tablet dan komputer. Line merupakan salah satu aplikasi sosial media yang digunakan untuk mengelola keperluan bisnis maupun organisasi. Line termasuk sesuatu yang baru. Line merupakan media sosial yang sangat diminati oleh millenial. Perpustakaan Universitas Airlangga melihat line merupakan suatu peluang untuk menyampaikan informasi kepada pemustaka. Line merupakan media sosial yang digandrungi oleh para pemustaka muda. Hal ini sejalan dengan pendapat Aditya Firmansyach Putra dalam tulisan Menyelamatkan Generasi Millenial Melalui Media Sosial yang dimuat dalam https://www.kompasiana. com/adityafirmansyach/5db115ea097f364c2750f75 2/menyelamatkan-generasi-millenial-melalui-mediasosial. Menurut Aditya, line merupakan salah satu media sosial yang disukai oleh para milenials. Media sosial sangat banyak menawarkan kemudahan yang membuat para milenials betah berlama-lama dalam menggunakannya. 


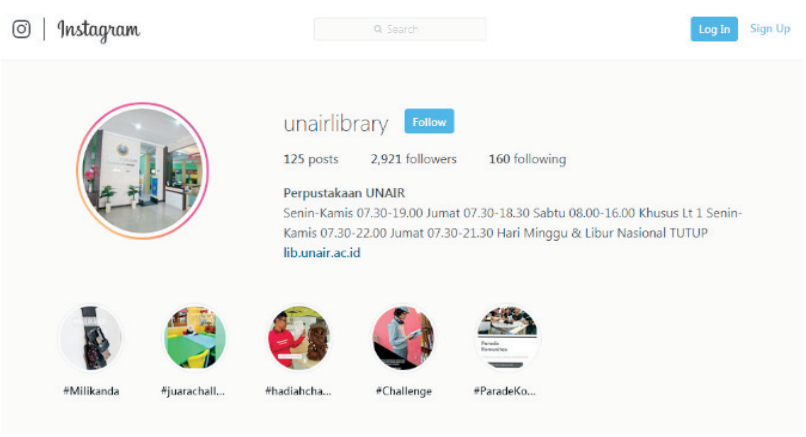

Gambar 5. Instagram Perpustakaan Universitas Airlangga

\section{Instagram}

Instagram adalah salah satu sosial media yang dapat dikatakan masih baru, namun Instagram sudah mampu memberikan hasil yang memuaskan bagi para pihak yang ingin memasarkan produk atau jasanya. Perpustakaan Universitas Airlangga juga memanfaatkan instagram sebagai salah satu media sosial untuk berkomunikasi dengan pemustaka melalui foto dan gambar. Instagram Perpustakaan Universitas Airlangga memiliki 128 posts, serta memiliki 3.080 followers dan 168 following.

6. Youtube

Siapa saat ini yang tidak mengenal Youtube? Semua orang sangat akrab dengan youtube. Youtube berdiri pada Februari 2005 dan telah berkembang dengan pesat. Pertumbuhan waktu menonton di youtube semakin cepat dan naik minimal 50\% dari tahun ke tahun selama 3 tahun berturut-turut. Youtube menjadi mesin pencari terbesar kedua di dunia setelah google. Maka memilih video sebagai alat promosi merupakan pilihan yang bijak. Metode ini cukup efektif untuk

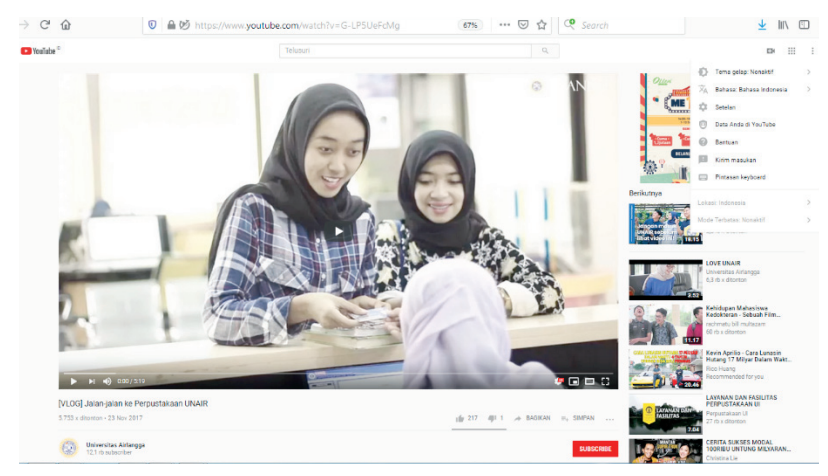

Gambar 6. Youtube Jalan-Jalan ke Perpustakaan Universitas Airlangga menarik minat konsumen atau pengguna. Pengguna merasa lebih mudah mengikuti suatu panduan dengan youtube. Perpustakaan Universitas Airlangga juga memilih youtube sebagai sarana promosi dan komunikasi dengan para pengguna. Melalui youtube informasi yang hendak disampaikan akan lebih mudah diterima dan jelas ditangkap oleh pemustaka. Perpustakaan Universitas Airlangga memanfaatkan youtube untuk membagi informasi mengenai sekilas informasi mengenai perpustakaan, suatu kegiatan, layanan terbaru dan lain sebagainya.

\section{KESIMPULAN}

Penerapan media sosial sebagai media promosi untuk perpustakaan merupakan kejelian pengelola perpustakaan dalam memasarkan produk perpustakaan. pemustaka tidak perlu susah payah untuk mencari informasi dengan datang ke perpustakaan. Pemustaka dapat melakukan sharing information melalui media sosial. Perpustakaan dapat melakukan indentifikasi kebutuhan informasi pemustaka, menetapkan inovatif promosi, sumber pendukung, penetapan media promosi. Sehingga perpustakaan dapat mengoptimalkan media sosial sebagai media efektif untuk memberikan pelayanan bagi pemustaka.

Perpustakaan Universitas Airlangga memiliki beberapa media sosial. Media sosial Perpustakaan Universitas Airlangga bertujuan untuk berinteraksi secara masif dan terstruktur dengan pengguna perpustakaan. Media sosial Perpustakaan Universitas Airlangga dikelola oleh Humas Perpustakaan Universitas Airlangga. Humas Perpustakaan Universitas Airlangga ini yang mengisi konten media sosial dan merespon pengguna yang bertanya atau memberikan masukan, kritik dan saran. Media sosial tersebut antara lain WhatsApp (wa), Facebook, Twitter, Line, Instagram, dan Youtube.

\section{DAFTAR PUSTAKA}

Aditya Firmansyach Putra. Menyelamatkan Generasi Millenial Melalui Media Sosial. https://www. kompasiana.com/adityafirmansyach/5db115ea097f364 c2750f752/menyelamatkan-generasi-millenial-melaluimedia-sosial. Diakses 3 Desember 2019.

Boyd, danah. 2009. "Social Media is Here to Stay... Now What?" Microsoft Research Tech Fest, Redmond, Washington, February 26.

Carr, CT., \& Hayes, RA. (2015). Social Media: Defining, Developing, and Divining. Atlantic Journal of 
Communication, 23, 46-45. https://www.tandfonline. com/doi/abs/10.1080/15456870.2015.972282

Kaplan M., Haenlein Michael. 2010. "Users of the world, unite! The challenges and opportunities of social media”. Business Horizons. 53 (1). p. 61.

Kotler, Philip dan Kevin Lane Keller. 2012. Marketing Management 13. New Jersey: Pearson Prentice Hall, Inc.
Nasrullah, Rulli. 2015. Media Sosial: Prosedur, Tren, dan Etika. Simbiosa Rekatama Media: Bandung.

Nawawi, H. Hadari. 1993. Metode Penelitian Deskriptif. Gajah Mada University Press. Yogyakarta.

Puntoadi, Danis. 2011. Meningkatkan Penjualan Melalui Sosial Media. Elex-Gramedia. 